\title{
Relationship between Body Image and Self-Esteem among Female Undergraduate Students of Behavioural Sciences.
}

\author{
${ }^{1}$ Abamara Nnaemeka C., $*^{2}$ Agu Solomon A. \\ 1. Department of Psychology, Nnamdi Azikiwe University, Awka, Anambra State, Nigeria. \\ 2. Enugu State University of Science And Technology, (Esut), Enugu State, Nigeria.
}

\begin{abstract}
The relationship between body image and self esteem was investigated among female undergraduate students of behavioural sciences using correlational design. Participants were 400 female undergraduate drawn from existing departments that made up faculty of Social Sciences, (Psychology, Sociology and Anthropology, Economics and Political Science) in Agbani Campus, Enugu State University of Science and technology. In relation to the outcome of the result, body image was confirmed to significantly related to self esteem which supported the hypothesis. The implications of the findings were discussed and recommendations were made for further studies.
\end{abstract}

Keywords: Behavioral Sciences, Body Image, Female Undergraduate Students, Relationship, Self Esteem.

\section{Introduction}

The self is a key construct in several schools of psychology, referring to either the cognitive and affective representation of one's identity or the subject of experience. The earliest formulation of the self in modern psychology from the distinction between the self as I, the subjective knower, and the self as me, the object that is known was earlier propounded by (James, 1891). Current views of the self in psychology position the self as playing an integral part in human motivation, cognition, affect and social identity (Sedikides \& Spencer, 2007).

However, the dimension of self that is discussed in this paper is self esteem. Self esteem is a term used in psychology to reflect a person's overall evaluation or appraisal of his or her own worth. Self esteem encompasses beliefs (for example, "I am competent", "I am worthy") and emotions such as triumph, despair, pride and shame. Self esteem can apply specifically to a particular dimension (for example "I believe I am a good writer and I feel happy about that') or have global extent (for example, 'I believe I am a bad person, and feel bad about myself in general').

Synonyms or near synonyms of self-esteem include: self-worth (American Heritage Dictionary, 2007), self-regard (American Heritage Dictionary, 2000), self-respect American Heritage Dictionary, 2007; Macquaire Dictionary, 1999), and self-integrity. According to the American Heritage Dictionary of the English Language, "self-love" is "the instinct or desire to promote one's well being" (American Heritage Dictionary, 2000).

The capacity to develop healthy confidence and respect for oneself (and for others) is inherent to human nature, since the mere fact of being able to think is the base of its suitability and the mere fact of being alive is the base of the right to make an effort to achieve happiness. Thus, the natural state of human being should correspond to a high self-esteem. Nonetheless, the fact is that there is a lot of people who, whether they acknowledge it or not, whether they admit it or not, have a level of self-esteem below the theoretically natural self worth (Branden, 2010).

This is due to the fact that, during development, and through life itself, people tend to move away from positive self-conceptualization or even decline approach to it. The reasons why this happens are diverse, and they can be found in negative influence from other people, self-punishment for breaking one's values or one's social group's values, or shortage of understanding or compassion for one's actions or others actions (Branden, 2010).

\section{Theories of Self Esteem}

Many early theories suggested that self-esteem is a basic human need or motivation. American psychologist Abraham Maslow, for example, included self-esteem in his hierarchy of need. He described two different forms of esteem: the need for respect from others and the need for self-respect, or inner self-esteem (Maslow, 1987). Respect from others entails recognition, acceptance, status, and appreciation, and was believed to be more fragile and easily lost than inner self-esteem. According to Maslow, without the fulfillment of the self-esteem need, individuals will be drawn to seek it and unable to grow and obtain self-actualization. 
Sociometer theory maintains that self-esteem evolved to check one's level of status and acceptance in one's social group. According to terror management theory, self-esteem serves a protective function and reduces anxiety about life and death (Greenberg, 2008). Carl Rogers, the greatest exponent of humanistic psychology, exposed that the origin of problems for many people is that they despise themselves and they consider themselves to be unvaluable and unwotrthy of being loved; hence the importance he gave to unconditional acceptance of client (Bonet 1997). Indeed, the concept of self-esteem is approached since then in humanistic psychology as an inalienable right for every person, summarized in the following sentence: "Every human being, with no exception for the mere fact to be it, is worthy of unconditional respect of everybody else; he deserves to esteem himself and to be esteemed". (Bonet, 1997). By virtue of this reason, even the most evil human beings deserve a human and considered treatment. This attitude, nonetheless, does not pretend to come into conflict with mechanisms that society has at its disposition to prevent individuals from causing hurt-of any type to others (Bonet, 1997).

One study has shown that inflating self-esteem by itself can actually decrease grades (Baumeister, Jennifer, Joachim, \& Kathleem, 2005). The relationship involving self-esteem and academic results does not signify that high self-esteem contributes to high academic results. It simply means that high self-esteem may be accomplished due to high academic performance (Baumeister, Campbell \& Krueger, 2003). High self-esteem correlates highly with self-reported happiness. However, it is clear, which if necessarily may lead to other human subjective thinking. (Baumeister, Jennifer, Joachim \& Kathleem, 2005). Additionally, self-esteem has been found to be related to forgiveness in close relationship, in that people with high self-esteem will be more forgiving than people with low self esteem (Eaton, Wardstruthers \& Santelli, 2006).

Another variable that is of interest to the present study is body image. Body image refers to a person's perception of the aesthetics and sexual attractiveness of their own body. Human society has all times placed great value on beauty of the human body, but a person's perception of their own body may not correspond to society's standards.

The concept of body image is used in numerous disciplines, including psychology, medicine, psychiatry, psychoanalysis, philosophy, cultural and feminist studies. The term is also often used in the media. A person body image is thought to be, in part, a product of their personal experiences, personality, and various social and cultural forces. A person's sense of their own physical appearance, usually in relation to others or in relation to some cultural "ideal" can shape their body image. A person's perception of their appearance can be different from how other actually perceives them.

A 2007 report by the American Psychological Association found that a cultural-wide sexual typing of girls (and women) was contributing to increased female anxiety associated with body image (APA, 2007). However, other scholars have expressed concern that these claims are not based on solid data (Ferguson, Winegard \& Winegard, 2011). Dolto (1984) has developed a theory of unconscious body image. Negative perceptions of a person's body image, such as a perception that they are fat, can in some cases lead to mental disorders such as depression or eating disorders such as bulimia nervosa, though there can be a variety of different reasons why these disorders can occur. Studies have found that females tend to think more about their body shape and endorse thinner figures than men even into old age (Ferraro, Muehlenkamp, Paintner, Wasson, Hager, \& Hoverson, 2008). Hawkins, Richard, Granley, Stein, Richards, Granley and Stein (2004), observed that when female undergraduates were exposed to depictions of thin women their body satisfaction decreased, but rose when exposed to larger models.

The desire to lose weight is highly correlated with poor body image, with more women than men wanting to lose weight. Kashubeck - West, Mintz and Weigold (2005), reported that when considering only men and women who desire to lose weight, sex differences in body image becomes inconsequential. Also, a study by Garner and Garfinkel (1980), demonstrated that those in professions where there is a particular social pressure to be thin (such as models and dancers), were much more likely to develop anorexia during their career, and further research suggests that those with anorexia have much higher contact with cultural sources that promotes weight-loss (Toro, Salamero \& Martiners, 1994).

Hence, female body shape or figure is the cumulative product of a woman's skeletal structure (her build) and the quantity and distribution of muscle and fat on the body. There have been wide differences on what should be considered an ideal or preferred body shape, both for attractiveness and for health reasons. These have varied among cultures simultaneously. As with most physical traits, there is wide range of normality of female body shapes. Human beings and their cultures have perennially focused attention on the female body as a source of aesthetic pleasure, sexual attraction, fertility, and reproduction.

Perception of physical attractiveness contributes to generalized assumptions based on those attractions. Across cultures, what is beautiful is assumed to be good; attractive people are assumed to be more extroverted, popular, and happy. This could lead to a self-fulfilling prophecy, as from a young age, attractive people receive more attention that helps them develop these characteristics. 
The main focus of this study centered on investigating the relationship between body image and self esteem. The effects of body image on self-esteem can be especially powerful during the teenage years. Although it's perfectly normal to have negative thoughts and feelings towards oneself once in a while, finding ways to be positive is the key to building a healthy body image and good self-esteem. The present study Contribute to the literature on body image and self-esteem. It was hypothesized that there will be a significant relationship between body image and self-esteem.

\subsection{Participants}

\section{Method}

Four hundred female undergraduate students of Enugu State University of Science and Technology participated in the study. These participants were randomly drawn from the existing Departments that made up faculty of social sciences, Agbani Campus, namely; Psychology, Sociology and Anthropology, Economics and Political Science department. In each of the Department, 100 female participants were selected; these participants were selected through simple random sampling. They were between the ages of 19 and 33 years with a mean age of 23.5 and standard deviation of 2.4years were used in the study.

\subsection{Instruments}

Two instruments were administered for the study. They include: Body Image Questionnaire and Index of Self Esteem

\subsection{Body image questionnaire}

The items were adapted from Jestes (1999) questionnaire on body image. The scale was designed to assess for the presence of body image distortions. The items for measuring body image distortion in the present study were drawn from this source. An example of an item from the body image questionnaire is: "I am satisfied with the shape of my body". The face and content validity of the items were ascertained by presenting the items to five experts, three social psychologist and two clinical psychologists. Also, a reliability study employing split-half reliability was done using 100 female undergraduate students of Enugu Campus of University of Nigeria. A reliability coefficient Alpha of.52 and a corrected value of .53 was obtained using Spearman Brown. The final instrument was a Likert type questionnaire with five options: Never $=1$, rarely $=2$, sometimes $=3$, often $=4$ and very often $=5$.

\subsection{Index of self-esteem}

This is a standardized psychological assessment instrument developed by Hudson (1982) and validated for use with Nigerian samples by Onighaiye (1996). The instrument contains 25 items designed to measure the self-perceived and self-evaluative component of self-concept which is the sum total of the self-perceived and the other-perceived views of the self held by a person. It is scored on a 5-point scale ranging from 1-5. Sample items on the scale include, "I think that I am a dull person", and "I think my friends find me interesting". Items $1,2,8,9,10,11,12,13,15,17,19,20$ and 24 are scored in direct direction while items $3,4,5,6,7,14,16,18$, $21,22,23$ and 25 are scored in reverse direction to obtain consistency of scoring. Separate norms have been reported for male and female Nigerian samples as follows: males $=30.89$, females $=32.04$ (Onighaiye, 1996). The Nigerian norms or mean scores are the basis for interpreting the scores of the participants. Scores higher than the norms indicate that the participants have low self-esteem. Index of self-esteem measures how poor a participant's self-esteem is.

\section{Procedure}

The two instruments were distributed and collected from the selected female students in the four Departments of faculty of social sciences with the aid of the researchers' students. Of 447 copies of each of the questionnaire returned, 47 were discarded because they were incorrectly filled. As a result, 400 copies of the two questionnaires were properly completed, scored and analyzed.

\section{Design/statistics}

A correlational design was adopted in the study while Pearson product moment correlation statistic was applied to analyze the formulated hypothesis. 


\section{Results}

6.1 Table 1: Mean scores and standard deviation of body image and self-esteem.

\begin{tabular}{|l|c|c|c|c|c|}
\hline & N & Minimum & Maximum & Mean & Std. Deviation \\
\hline Body image & 400 & 17.00 & 65.00 & 47.63 & 6.94 \\
\hline Self esteem & 400 & 8.00 & 69.00 & 32.85 & 11.33 \\
\hline $\mathrm{N}$ & 400 & & & & \\
\hline
\end{tabular}

A mean score of 47.63 was obtained on body image in comparison to a normative score of 49.34 obtained from pre-testing indicating an optimum score since a score above 49.34 shows a high score on body image while a score below it indicates a low score. The optimum score is an average score that typifies $50 \%$ of the responses indicative of a positive body image that may be average or high.

On the other hand the normative score for self-esteem for females is 32.04 in comparison to 32.85 which is above the standard and also indicates low self esteem. The above results show that an average degree of perception of body image correlated with low self-esteem. This reveals that low self-esteem correlated with distorted body image found to be average but below the standard of being high.

6.2 Table 2: Regression on the relationship between body image and self-esteem

\begin{tabular}{|l|l|c|c|}
\hline & & Body image & Self esteem \\
\hline Body image & Pearson Correlation & 1 & -.318 \\
& Sig. (2-tailed) & 400 & .000 \\
& $\mathrm{~N}$ & -.318 & 400 \\
\hline Self esteem & Pearson Correlation & .000 & 1 \\
& Sig. (2-tailed) & 400 & 400 \\
& $\mathrm{~N}$ & & \\
\hline
\end{tabular}

Correlation is significant at the 0.01 level (2-tailed)

A significant correlation of -0.32 was obtained at $\mathrm{P}<.01$ between body image and self esteem which is above a criteria value of 0.30 (Pedhazur, 1997). This has confirmed the hypothesis that there will be a significant relationship between body image and self-esteem. This means that body image is inversely related with selfesteem based on negative correlation. It appears that low self-esteem significantly correlated with distorted body image, based on the fact that 32.85 is above the norm of 32.04 indicating low self-esteem.

\section{Discussion}

Body image contributes to our perception of self in the society. People have overall sense of body image which affects their emotions, feelings and self worth and recognition.

In one study it was found that females tend to think more about their body shape and endorse thinner figures than men even into old age (Ferraro, Muehlemkamp et al, 2008). This is a clear indication of the fact that females have a sense of body image which also influence their self worth and esteem and also make them to become recognized.

In another study it was observed that the desire to lose weight is highly correlated with poor body image, with more women than men wanting to lose weight (Kashubeck et al 2005). This shows a sense of concern with body image which on the other hand affects one's sense of judgement and feelings about self.

The above studies revealed that women have more desire and concern about body image than men. In addition, terror management theory postulated that self-esteem serves as a protective function and reduces anxiety about life and death (Greenberg, 2008). This over concern and too much dependents on body image and self-esteem on the part of females is a clear indication that there is something between body image and self esteem, showing that the two may have a relation or influence one another depending on the context. In relation to the outcome of this investigation body image was confirmed to be significantly related to self-esteem which basically supports previous investigations in this area. Further, an observed significant relationship observed between body image and self-esteem occurred in negative dimension indicating distorted body image and low self-esteem when compared with certain existing criteria. Even though body image is low and above average showing distortion but it correlated with low self-esteem showing weak recognition and perception of self on the part of females.

Moreover, multiple correlations were observed in relations to the variables investigated which revealed significant correlation between high self esteem and body image $(-.277, \mathrm{P}<0.01)$; high self esteem and high body image $(-.267, \mathrm{P}<0.01)$; high self esteem and low body image $(-.997, \mathrm{P}<0.01)$; low self esteem and body image $(-.319, \mathrm{P}<0.01)$; and low self esteem and high body image $(-.327, \mathrm{P}<0.01)$.

Apparently, the multiple correlations are supportive of the hypothesis investigated indicating that self esteem at different levels also relates with body image at different levels. A strong observation which serve as an implication for the outcome of this investigation focus on the fact that an individual's level of self esteem serves as a correlate to one's perception of body image, in that, as body image varies one's self esteem may appreciate or depreciate. 
In view of the above findings, observation revealed that future researchers should consider it pertinent to consider the economic recession in the social milieu of the participants, the aspiration for academic recognition, and social dependency of people who are under constituted authority (Parental/academic) when formulating another research in this area.

\section{References}

[1]. American Psychological Association (2007). "Report of the APA Task force on the sexualization of girls" (PDF).

[2]. Baumeister, R.F.; Campbell, J.D.; Krueger, J.I.; Vohs, K.D. (2003). "Does high self-esteem cause better performance, interpersonal success, happiness, or healthier lifestyles"? Psychological science in the public interest 4(1): $1-44$.

[3]. Baumeister, Roy F.; Jennifer D. Campbell, Joachim I. Krueger and Kathleen D. Vohs (2005). "Exploding the self-esteem myth". Scientific American.

[4]. Eaton, J; wardstruthers, C; Santelli, A (2006). "Dispositional and state forgiveness: The role of self-esteem, need for structure, and narcissism". Personality and individual difference 41 (2): 371 - 380

[5]. Ferguson, C.; Winegard, B., Winegard, B.M. (March 2011). "Who is the fairest one of all: How evolution guides peer and media influences on female body dissatisfaction". Review of general Psychology 15(1): $11-28$

[6]. Ferraro, F. R; Muehlenkamp, J.J; Paintner, A; Wasson, K; Hager,T \& Hoverson, F (2008). Aging, Body Image, and Body Shape. Journal of General Psychology 135 (4): 379-392, 14p

[7]. Francoise Dolto (1984). L'image inconscient du corpus. Paris: Seuil, ISBN4202018302

[8]. Garner DM, Garfinkel PE. (1980) "Socio-cultural factors in the development of anorexia nervosa". Psychol Med, $10(4)$, 647 - 56. PMID 7208724

[9]. Greenberg, J. (2008). Understanding the vital human quest for self-esteem. Perspectives on psychological science, 3, $48-55$.

[10]. Hawkins, Nicole; Richards, P. Scott; Granley, H. Mac; Stein \& David M., N (Spring 2004). "The impact of exposure to the thin-ideal media image on women". Eating disorders 12(1): $35-50$

[11]. James, W. (1891). The principles of Psychology, vol. 1. Cambridge, MA: Harvard University Press.

[12]. Kashubeck - West S, Mintz LB, Weigold 1 (October, 2005). "Separating the effects of gender and weight-loss desire on body satisfaction and disordered eating behaviour". Sex roles 53(7-8): $505-518$

[13]. Maslow A. H. (1987). Motivation and Personality $\left(93^{\text {rd }}\right.$ Ed.). New York: Harper \& Row.

[14]. Pedhazur E. J. (1997). Multiple Regression in Behavioural Research ( $3^{\text {rd }}$ Ed). Orlando.FL: Harcourt Brace.

[15]. Sedikides, C. \& Spencer, S.J. (2007). The self. New York: Psychology press.

[16]. Sonia Tucca; Jennifer Peters, S; Peters, J (2008 Nov). "Media influences on body satisfaction in female students" (PDF). Psicothema 20(4): $521-4$

[17]. Toro J. Salamero M. Martinez E. (1994) “Assessment of sociocultural influences on the aesthetic body shape model in anorexia nervosa”. Acta psychiatrica scandinavica, 89(3), 147 - 51. PMID 8178671

\section{First Author (MAPA 1998, SMNACP 2005, SMAPA 2012)}

The first author of this paper holds a B.sc in general Psychology in 1997 and M.sc in Clinical Psychology in 2004 from the University of Ibadan, Nigeria. He also holds a Ph.D in Clinical Psychology in 2013 from Nnamdi Azikiwe University, Awka. He taught in National Open University of Nigeria, Owerri Study Centre, ImoState from 2006 to 2007, before joining Nnamdi Azikiwe University, Awka in 2007. He is a member of Nigerian Psychological Association 1998; senior member of Nigerian Association of Clinical Psychologists 2005; senior member of Nigerian Psychological Association 2013. He is also a practicing Clinical Psychologist. His research interest is on mental health, with special interest on psychotic disorders, sleep disorders. Other areas are; Psycho-neurology; Demographic and psychosocial predictors of cardiovascular illness, sexual abnormalities and deviation, Child and Adult psychopathology, cognitive psychology and health Psychology.

\section{Second Author}

The second author of this paper holds a B.sc in general Psychology from Enugu state University of Science and Technology, Enugu Nigeria and M.sc in Social Psychology from University of Nigeria, Nssukka. He is currently on his Ph.D programme in Social Psychology in Nnamdi Azikiwe University,Awka, Nigeria, and he currently teaching in Enugu State University of Science and Technology, Enugu Nigeria.

\section{Acknowledgment}

Our special thanks go to the female students of Faculty of Social Sciences, Enugu state University of Science and Technology, Enugu Nigeria for being participants of this study. Their maximum cooperation made this study a reality. 